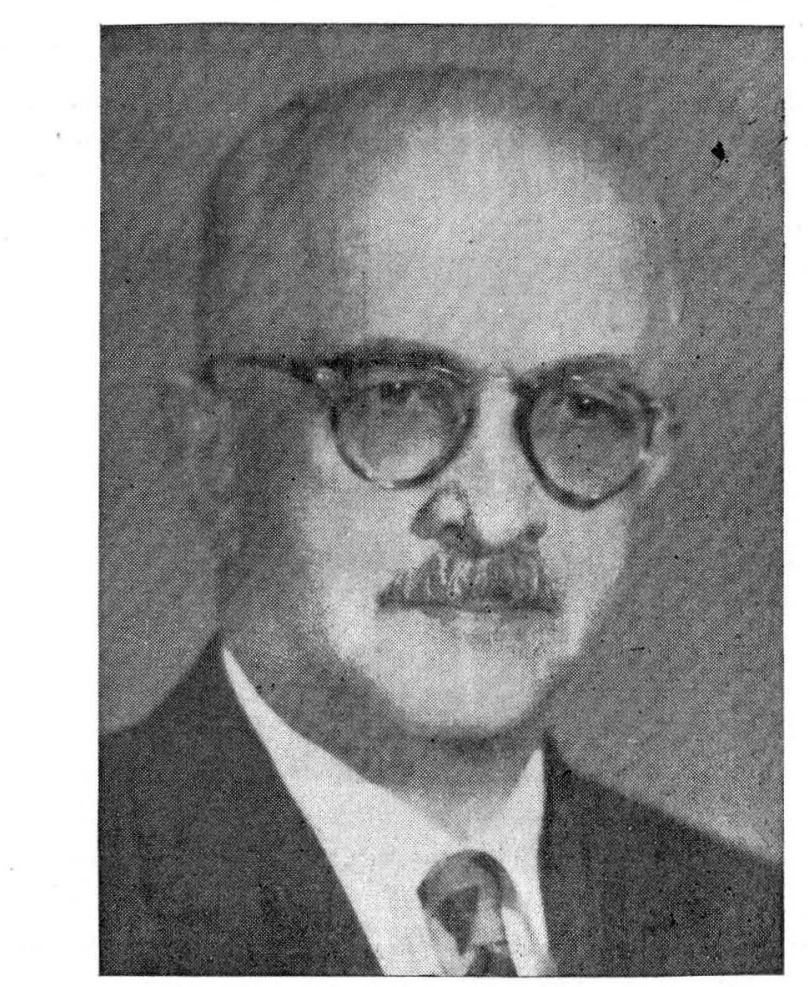

\title{
Prof. JOSE DEL CARMEN ACOSTA
}

La personalidad del Profesor José del Carmen Acosta, fallecido a principios de este año, invita al análisis de sus virtudes que se reconocieron por todos, a lo largo de esa vida cargada de méritos.

La disciplina del estudio lo llevó a tener para su Cátedra de Clínica Obstétrica, un acopio de conocimientos que siempre tenían el calor de lo nuevo en Medicina y el brillo del éxito en las aplicaciones prácticas sobre las pacientes.

Como fundador de la Sociedad Colombiana de Obstetricia y Ginecología, le dedicó su saber y su entusiasmo; estuvo siempre atento a que se mantuviera a un alto nivel científico y sus sesiones contaban con su presencia y su opinión que siempre contribuian a hacer la discusión clara y serena.

Cuando se trató de darle a la Sociedad un medio de expresión, contribuyó tesoneramente a crear esta Revista que hoy se enorgullece 
al dedicar sus páginas a que recojan los frutos de lo que él sembró en sus discípulos $y$ en todas las organizaciones que contaron con su dirección. En este ejemplar se publica lo que el Cuerpo Médico siempre le reconoció y lo que dijo con motivo de su muerte fué una afirmación de los elogios que en vida pudo oir, cada vez que sus alumnos y colegas tuvieron oportunidad de declararlo en su presencia.

Cuando la Medicina Colombiana sintió los primeros pasos de una Socialización organizada oficialmente y que hoy se sostiene gracias a los mismos Médicos, tomó la bandera de su Sociedad y la hizo ondear orgullosa hasta conseguir que los derechos de sus asociados, fueran por lo menos clasificados en conjunto antes que caer en la fosa común de una nómina tabulada.

Por su profundo conocimiento de la anatomía, de la fisiología y la patología de los órganos genitales de la mujer, fué el primer integrado en Obstetricia y Ginecología por derecho propio. Brilló en el estudio de la paciente, brilló en el diagnóstico y brilló en la acción. Pero lo que más descuella en el recuerdo de su vida, es la manera como ejerció su profesión. Dedicado como el que más a una tarea sin horario, se entregó de lleno a mitigar la angustia de la mujer embarazada o en trabajo de parto, ya en el hospital o en su ejercicio particular.

El tono de su voz diluía el temor; la explicación que daba a la paciente, vencía la tensión; su gesto amable mitigaba el dolor; así con este comportamiento médico, dominó el círculo temor, tensión, dolor, para colocarse también de primero en la aplicación de la sicoprofilaxis del embarazo y del parto.

Esta es la Escuela Médica de honestidad, trabajo y ciencia que nos legó el Profesor Acosta y con ella honraremos su memoria. 